\title{
Papers
}

\section{Costs of saving for retirement in South Africa}

Received (in revised form): 20th July, 2005

\section{Rob Rusconi}

is Client Portfolio Manager at SEI Investments South Africa. He has worked in a variety of functions for life offices and consulting firms both in South Africa and the United Kingdom and spent a year setting up the fund ratings business at FT.com, London. He has a BSc from the University of Cape Town, is a fellow of the Institute of Actuaries and his primary research interest is old age reform in South Africa and other parts of Africa.

\begin{abstract}
How much are South Africans paying for their retirement funding? Whether in occupational plans or private supplementary arrangements, workers pay for the opportunity to save for retirement through a variety of charges that erode the prosperity of the retirement years. This paper analyses the administrative charges paid by South Africans saving for retirement in three tax-effective vehicles: occupational retirement funds, individual life products and unit trust arrangements, using a model designed to evaluate the lifetime impact of these charges. The analysis presented here suggests that retirement funds are cheapest, followed by unit trusts and then individual life products. These results are consistent with the flexibility of the more costly products. Overall, however, charges appear to be high. Comparison with international benchmarks confirms these concerns. Policymakers should be addressing this through stronger disclosure requirements and consideration of a standardised national product and potential charge ceilings.
\end{abstract}

Keywords: retirement; comparative costs; South Africa; savings vehicles

\section{South Africa's retirement saving landscape}

South Africa has an advanced, formal, tax-effective, pension-saving sector and a successful means-tested social security system for the aged. But many South Africans do not receive significant benefit from either of these systems.

\section{Formal sector}

Rob Rusconi 30 Balder Road, Douglasdale, 2021 South Africa

Tel: +27 114620149 e-mail rusconihome@wol.co.za
The absence of comprehensive old age social security benefits for the middle-class and affluent sectors has surely contributed to the development of South Africa's successful insurance and pensions saving environment. Indeed, according to the South African Government, Taylor Report, 2002, 'South Africa's private pension and insurance sectors are estimated to be the largest in the world relative to gross national product. ${ }^{1}$

South Africans receive tax incentives to save for retirement through occupational pension funds and through individual tax-efficient savings arrangements, either unit trusts or life policies, known as retirement annuities. The Taylor Report records pension fund contributions of R54.3bn per annum, 14 per cent of total personal remuneration 
and a further R8bn paid into retirement annuity funds. The report suggests that a large proportion of the R $27 \mathrm{bn}$ paid into regular premium life assurance is also intended to provide benefits payable at retirement. HelpAge International $(2003)^{2}$ quotes the Katz Commission estimate that tax incentives to the formal sector cost the South African Treasury 1.7 per cent of GDP annually.

The efficiency of the formal sector retirement system and the resulting impacts on the benefits that it provides to its beneficiaries are at the core of this research paper.

\section{Social security grants}

At the other end of the scale is an extensive system of social grants to the elderly. This is a non-contributory means-tested flat-rate system that in the late 1990 s paid R520 per month, ${ }^{3}$ just over 2.5 times the per capita income of black South Africans at the time. Increases to grants are ad hoc, based on affordability, but have been rapid in recent years, most recently payable at R740 monthly. It is financed by government from general revenues and costs approximately 1.4 per cent of GDP. ${ }^{4}$ The February 2004 briefing to Parliament puts the number of beneficiaries for 2003 at over 2 million.

A number of commentators have lauded the system, suggesting that in many of South Africa's poorest communities, the old-age grant supports not just the aged but many of their dependents as well.

'The generosity and universality of South Africa's pension system are unique by developing country standards ... The system is probably the most effective programme in targeting and reaching economically vulnerable groups. Its benefits reach deep into poverty-stricken communities. ${ }^{5}$
The analysis described in this paper does not cover social security grants.

\section{The uncovered middle}

South Africa does not have a retirement savings environment consistent with the World Bank's definition of a three-pillar system.

- The social security system is pitched at a level that fends off poverty rather than providing substantially for old age.

- The occupational system is not mandatory and preservation of savings until old age is not required. Recent statutory developments have been aimed at ensuring fair treatment of individuals leaving a job early rather than ensuring adequate coverage at retirement.

South Africa has a successful formal savings environment and highly lauded social security safety net, but this does not mean that the system as a whole can be described as successful. The Taylor Commission points out that 60 per cent of South Africa's poor receive no social security transfers. ${ }^{6}$

\section{Purpose of the analysis}

South Africa's pension fund legislation is dated and currently under review by policymakers. This research is intended to contribute to the analysis and debate around this review.

Why then a study of costs? Most countries provide a significant public sector element to retirement saving. In contrast, working citizens in South Africa depend strongly on the private sector in the form of occupational retirement funds and a variety of additional voluntary savings options. Understanding the costs to which savers are subject is an important first step towards 
establishing a sensible framework for regulating savings vehicles.

Costs make a difference; they affect the old age prosperity of citizens and, ultimately, the degree to which the population depends on the State for financial support in old age. ${ }^{7}$

\section{Methodology}

Should the analysis consider charges or actual costs? As the objective of this paper is to determine the impact of these expenses on the retirement savings of the individual, the view has been taken that measuring charges is more important than determining the costs incurred in provision of the services. Furthermore, in the long term, in a competitive environment, the gap between charges and costs should be fairly stable.

\section{Charge measures}

The most common types of charges experienced in the analysis are:

- life office products: a fixed monthly deduction, a percentage of each contribution and an annual percentage of the assets, commonly deducted monthly, although a fixed inception fee also applies;

- unit trust products: a percentage of each contribution and an annual percentage of the assets;

- retirement funds: an annual percentage of the assets for asset management and regular annual costs for administration that are expressed as a percentage of assets, a percentage of contribution or a percentage of the salary payroll on which the contribution calculation is based.

To allow for different types of charges, two summary statistics have been calculated in all instances. The reduction in yield is the percentage point reduction in annual return over the period of saving that is equivalent in overall impact to the erosion of value due to all charges. The charge ratio is the corresponding percentage reduction in maturity value equivalent in overall impact to the erosion of value due to all charges. ${ }^{8}$

The reduction in yield and charge ratio each have advantages and disadvantages. And each makes more sense in an environment in which charges are commonly quoted in that way. Quoting both figures is consistent with the approaches of international researchers, for example, Whitehouse (2000), ${ }^{9}$ Murthi et al. (1999), ${ }^{10}$ James et al. (2001), ${ }^{11}$ Devesa-Carpio et al. $(2003)^{12}$ and Diamond (1999). ${ }^{13}$

'When comparing funds or systems which rely on different types of charge, reliance on a single measure can be misleading, and the best approach is to use both the charge ratio and the charge as a proportion of assets. ${ }^{14}$

\section{Areas excluded from the analysis}

In an effort to reduce the complexity and volume of analysis the following types of charges are not covered by the research:

- Trading costs, which include broker fees, stamp duty and the bid-offer spreads common to securities exchange shares.

- Alteration costs, the charges resulting from interrupted or altered patterns of saving. This paper avoids modelling either the cost of alterations or interrupted periods of saving.

- Costs arising from what is here termed protection against anti-selection, for example annuity purchases. Typically, the mortality calculations of the insurer for pricing the annuity allow for some 
degree of anti-selection by the purchasers. Insurers are conservative in their estimates and annuitants lose out as a result.

These exclusions do not invalidate comparison, but they limit the breadth of application of the analysis.

\section{Methodology and choice of parameters}

A cash flow model has been developed to summarise the impact of charges. It is more appropriate in this context than the formula method used in Whitehouse $(2000)^{15}$ and Devesa-Carpio et al. (2003), ${ }^{16}$ as it is more flexible and allows better calculation of the impact of the variety of charges encountered, particularly under individual life policies. ${ }^{17}$

Neither of the charge measures is particularly sensitive to the choice of financial parameters, ${ }^{18}$ but nevertheless it makes sense to select parameters that are sensible and likely to remain appropriate for some time to come. These are set out in Table 1. The choice of parameters has been guided by the following criteria:

- Parameters need to be appropriate to the long term, because saving for retirement is a long-term process, but without being inappropriate to the current environment.

- The differences between parameters are more important than the nominal values.

- Parameters must be reasonable in the context of the South African saving environment but should be, as far as possible, consistent with the corresponding parameters used by other researchers, to make possible a fair comparison of results.

These are in line with the assumptions
Table 1: Model parameters

\begin{tabular}{lc}
\hline & Annual rates (\%) \\
\hline Inflation rate & 5 \\
Salary growth & 7 \\
Investment return & 10 \\
\hline
\end{tabular}

used by other researchers. Murthi et al. $(1999)^{19}$ use the basis for the Minimum Funding Requirements, which specifies an inflation rate of 4 per cent, equity returns of 9 per cent nominal and wage growth 6 per cent nominal. James et al. $(2001)^{20}$ use annual real wage growth and interest rates of 2 per cent and 5 per cent respectively.

No allowance has been made for mortality in these calculations, assuming that its impact is roughly neutral and that benefits paid on death are approximately equal to the fund accumulated at that time in whatever vehicle is used by the saver.

As costs in occupational funds are pooled across the membership, the cash flow model does not lend itself to analysis of costs in this structure. Funds are analysed on the basis of current costs, contributions and assets, the assumption being that these relationships remain constant.

\section{Analysis of costs}

Tax complicates the comparison across channels. In all cases, qualifying contributions are exempt from tax at the full marginal rate, but there are differences in the ceilings to the exempted amounts. Assets under management during the accumulation phase are taxed and this may impact the three channels in different ways. Rules concerning the way in which these assets may be invested also differ. ${ }^{21}$

No attempt has been made to incorporate these differences in the 
analysis. This paper is not intended to provide a detailed comparison of the savings channels, but rather a reasonably comprehensive analysis of the cost features of each.

\section{Occupational retirement funds}

The South African retirement fund environment is complex. ${ }^{22}$ The analysis in this paper covers a subsection of the country's occupational funds referred to as 'self-administered funds'. These are funds 'that invest their assets with bodies and institutions in the public and private sectors of the economy on their own behalf. ${ }^{23}$ They form the largest pool of occupational retirement funds and this is where the Registrar also puts the greatest weight of his analytical effort. These funds are a natural area for analysis impacting the choices faced by South Africans saving for retirement.

The Registrar was unable to provide the data required at fund level. Analysis of occupational funds has been complicated by this and other factors such as undisclosed costs, subsidy of expenses by the fund sponsor, a variety of measurement methods and the need to utilise a number of information sources. The analysis in this section is therefore somewhat piecemeal. It is hoped that it encourages better disclosure of charges and a more uniform basis, allowing funds to understand costs incurred and authorities to monitor industry trends far more closely.

\section{Registrar of pension funds}

The Registrar publishes information concerning fund expenses in his annual report. The 2003 report quotes a total cost for self-administered funds of R2.9bn, equivalent to 13.1 per cent of total annual contributions or 0.799 per cent of total assets. Breaking this down, investment advisers' fees are equivalent to
4.9 per cent of contributions or 0.302 per cent of total assets. Administration fees and consultancy fees are equivalent to 5.4 per cent of contributions or 0.327 per cent of assets (Registrar of Pension Funds, 2003 and author's calculations). ${ }^{24}$

As shown below, analysis suggests that these figures significantly understate actual costs.

\section{Asset management costs}

Information on asset management costs can be difficult to obtain from the accounts of retirement funds because they are sometimes not disclosed, having been deducted from gross investment performance in the income figures. Asset management fees have been analysed instead using an Alexander Forbes survey of fees quoted by the asset managers themselves. $^{25}$

The results presented below are based on an equal weighting of asset managers. Data have been excluded where unclear: performance-related fees are difficult to include but are rare; negotiable fees for large funds have been included on a consistent basis; only one passively managed portfolio is included in the survey and that has been excluded; with-profit portfolios from insurers, here known as guaranteed funds, have been excluded due to a lack of transparency of fee structure. Of 49 portfolios available from 23 different managers (not counting guaranteed funds), 42 have been included in this analysis.

Table 2 illustrates the results; further details are available from the author. For a self-administered fund of average size of approximately R $150 \mathrm{~m}$, asset management charges average around 0.60 per cent and most funds of this size can expect to pay between 0.50 per cent and 0.70 per cent per annum. Smaller funds might expect to pay up to 0.15 percentage points more and larger funds around 0.10 less. 
Table 2: Institutional asset management costs in South Africa, equal-weighted managers

\begin{tabular}{cll}
\hline $\begin{array}{l}\text { Amount } \\
\text { invested }(\mathbf{R m})\end{array}$ & $\begin{array}{l}\text { Mean annual charge } \\
\text { as \% of assets }\end{array}$ & Standard deviation (\%) \\
\hline 30 & 0.69 & 0.13 \\
100 & 0.63 & 0.11 \\
300 & 0.56 & 0.09 \\
1,000 & 0.51 & 0.09 \\
\hline
\end{tabular}

Source: Alexander Forbes and author calculations.

Table 3: Retirement fund cost ratios for participating actuarial valuation providers

\begin{tabular}{llccccc}
\hline Provider & DB or DC & $\begin{array}{l}\text { Mean ratio (\%) } \\
\text { (unweighted) }\end{array}$ & $\begin{array}{l}\text { Mean ratio (\%) } \\
\text { (weighted) }\end{array}$ & 75th & \multicolumn{2}{c}{$\begin{array}{c}\text { Percentiles (\%) } \\
\text { 50th }\end{array}$} \\
\hline A & DC & 8.9 & 5.1 & 10.8 & 8.2 & 4.8 \\
B & DC & 11.5 & 5.9 & 13.0 & 8.1 & 4.2 \\
B & DB & 16.0 & 12.3 & 20.3 & 11.0 & 6.7 \\
C & DC & 9.0 & 5.8 & 11.5 & 7.6 & 5.6 \\
C & DB $^{*}$ & 9.8 & 4.4 & 9.4 & 4.5 & 3.4 \\
\hline
\end{tabular}

DB: defined benefit plans; DC: defined contribution plans. ${ }^{*}$ The number of observations in this group is low and the results are unreliable.

Note: The cost ratio used is the total reported administration cost, including actuarial fees, for the most recent reporting period, divided by the total employer and member contributions, net of risk benefit contribution costs. Weighted ratios are weighted by membership. Number of funds with each provider withheld for confidentiality of data sources.

Source: Participating actuarial consultants and author calculations.

These figures are considerably higher than the approximately 0.30 per cent reported by the Registrar.

\section{Administration and consulting costs}

Fees for administration are typically charged as a percentage of the total pensionable salary of members. In order to compare appropriately with other products, more suitable measures such as percentage of contribution or percentage of assets must be determined.

As centralised information was not available, fund costs were requested from companies responsible for conducting actuarial valuations of these funds. Four companies participated in the study, covering 242 funds and a total of 127,450 members.

Table 3 sets out a summary of results and Table 4 demonstrates the relationship between charges and the size of the fund.

The data suggest median charges for defined contribution arrangements of around 8 per cent. The corresponding analysis for defined benefit funds is unreliable owing to a general shortage of data, the larger data set suggesting a median of around 11 per cent and the smaller set 5 per cent. In all cases, there are considerable ranges around the medians. With the exception of the small set of defined benefit funds (Provider C), these figures are significantly higher than the mean industry ratio for self-administered funds of 5.4 per cent. ${ }^{26}$

The fourth subject provided a large set of funds but without the cost of death benefit premiums, which were removed to express contributions net of risk benefit costs. After adjustment for this difference, the results for this data set were found to be within the range of the providers shown in Table 3 .

Table 4 shows the strong relationship between administration costs and the number of members. The defined benefit funds suffer paucity of data, but for each of the defined contribution funds the relationship is clear. For these funds, the 
Table 4: Regression statistics for retirement fund cost ratios versus $\log _{e}$ (membership) for participating actuarial valuation providers

\begin{tabular}{llllllll}
\hline & & R-square & Slope & \multicolumn{4}{l}{ Regression ratios (\%) } \\
Provider & DB or DC & statistic & co-efficient & $\boldsymbol{p}$-value & $\mathbf{5 0 0 \text { members }}$ & $\mathbf{1 0 0}$ members & 40 members \\
\hline A & DC & 0.3945 & -0.0234 & 0.0040 & 6.6 & 10.3 & 12.5 \\
B & DC & 0.0767 & -0.0307 & 0.0223 & 9.6 & 14.6 & 17.4 \\
B & DB & 0.0428 & -0.0246 & 0.2125 & 12.0 & 16.0 & 18.2 \\
C & DC & 0.2491 & -0.0254 & 0.0000 & 5.8 & 9.9 & 12.2 \\
C & DB $^{\star}$ & 0.4882 & -0.0650 & 0.0228 & $-0.1^{*}$ & 10.4 & 16.4 \\
\hline
\end{tabular}

DB: defined benefit plans; DC: defined contribution plans. ${ }^{\star}$ The number of observations in this group is low and the results are unreliable. The lowest cost ratio in the set is 2.1 per cent.

Note: The cost ratio used is the total reported administration cost, including actuarial fees, for the most recent reporting period, divided by the total employer and member contributions, net of risk benefit contribution costs. 'Regression ratios' show the points on the regression line for each membership specified. The $p$-value provides a measure of the significance of the overall fit and of the slope $t$-statistic.

Source: Participating actuarial consultants and author calculations.

regressed ratio for a fund with 40

members is more than twice the corresponding ratio for a fund with 700 members.

Information provided for a much larger set of defined contribution funds not subject to valuation confirms these patterns. Median ratios in size bands range from approximately 6.0 per cent for funds of more than 1,000 members to over 22.0 per cent for funds of 20 members or fewer.

A charge ratio range of 6-12 per cent of contributions captures an acceptable proportion of all funds, but ratios as low as 4 per cent and as high as 22 per cent provide reasonable estimates of the more extreme circumstances of some funds, without including all cases. Using the Registrar's figures for industry contributions and assets, these ratios are equivalent to a 'core range' of $0.37-0.73$ per cent of assets and an 'outside range' of $0.24-1.34$ per cent.

\section{Other retirement fund costs 27}

The Registrar's report suggests that these costs together average around 2.8 per cent of contributions. This may represent an understatement of reality, consistent with the experience for asset

management and administration costs, but it is difficult to confirm or refute this.

\section{Summary of analysis of occupational retirement funds}

Retirement fund costs are extremely varied. There is a clear relationship between fund size and cost incurred. But there is also a considerable element of variation apart from the size relationship.

Combining the analysis discussed earlier, and converting ratios to ensure consistency of measurement, gives a 'core range' of between 17.0-27.1 per cent of contributions, equivalent to a range of 1.04-1.65 per cent of assets per annum. An 'outside range' of between 13.4-38.7 per cent of contributions is sufficient to encompass mean costs within any subdivision by size, but not outliers. As a percentage of assets, these figures are equivalent $0.81-2.36$ per cent of assets per annum.

\section{Individual policies}

Conventional business wisdom suggests that life assurance policyholders are not sensitive to cost. This suggests that analysis of charges in this sector is more important than in others.

\section{Methodology and data}

The model and assumptions set out in the section 'Methodology and

parameters' are used to analyse these 
Table 5: South African life policy cost ratios for 40-year saving period at average asset management fee

\begin{tabular}{lll} 
& Reduction in yield (\%) & Charge ratio (\%) \\
\hline R200 starting premium & & \\
Firm A retirement annuity & 2.82 & 43.38 \\
Firm A provident fund & 1.49 & 26.58 \\
Firm B retirement annuity & 2.01 & 33.78 \\
Firm C retirement annuity & 2.89 & 44.13 \\
Firm D retirement annuity & 2.81 & 43.30 \\
Firm D provident fund & 2.55 & 40.37 \\
R1,000 starting premium & & 41.01 \\
Firm A retirement annuity & 2.60 & 24.76 \\
Firm A provident fund & 1.37 & 30.83 \\
Firm B retirement annuity & 1.79 & 41.45 \\
Firm C retirement annuity & 2.64 & 41.74 \\
Firm D retirement annuity & 2.67 & 38.65 \\
Firm D provident fund & 2.40 & \\
\hline
\end{tabular}

Source: Participating life offices and author's calculations. Assumed 10 per cent annual rate of return on assets and 7 per cent annual rate contribution growth.

costs. Model policyholders earning respectively R24,000 and R120,000, and contributing 10 per cent of their income to their policy are assumed. ${ }^{28}$ The charge ratio and reduction in yield have been calculated for a 10-, 20-, 30- and 40-year saving term.

Providers offer a range of investment options at different costs. The mid-point of the range of asset management charges has been used for illustration, but the extremes have been calculated as well. With-profit products have been excluded due to non-transparency of costs to the client, consistent with their treatment under occupational retirement funds.

Data have been obtained from four firms covering approximately 80 per cent of the market. All of these firms refer to their standard tax-exempt product as a retirement annuity. Two of these firms also offer a low-cost alternative with significantly reduced choice and lower charges, designed principally for those small groups of employees for whom an occupational fund is impractical. These have been referred to as provident funds.

\section{Results}

Results are summarised in Table 5; further detail is available from the author.
- Charges are high: The mean unweighted reduction in yield across all six contracts for policies with contributions starting at R200 per month is 2.43 per cent per annum and the equivalent charge ratio 38.6 per cent.

- Charges are higher for small policies: Not surprisingly, owing to the fixed component of the policy fee, ratios are higher for low-contribution policies. All contracts show this effect to some extent, depending on the relationship between fixed and variable costs.

- The provident fund arrangements are cheaper than their retirement annuity counterparts: The firms that offer both retirement annuities and provident funds have succeeded in providing a cheaper alternative to the retirement annuity, though the difference is greater in the case of Firm A.

- Three of the retirement annuity products have very similar charges: Firm B offers by far the best value for money in a retirement annuity. The other three retirement annuities are remarkably close in their charging levels, despite having very different charging structures. Differences are greater at shorter policy terms.

- The range of costs is high: The difference 
Table 6: South African mean unit trust cost ratios for 40-year saving period (standard deviation in brackets)

\begin{tabular}{lll}
\hline & Reduction in yield (\%) & Charge ratio (\%) \\
\hline Cash & $0.74(0.37)$ & $14.14(6.22)$ \\
Income & $0.93(0.27)$ & $17.70(4.51)$ \\
Bonds & $0.97(0.28)$ & $18.25(5.03)$ \\
Balanced & $1.73(0.28)$ & $29.92(3.98)$ \\
Equity & $1.80(0.34)$ & $30.83(4.56)$ \\
Equity passive & $0.94(0.27)$ & $17.64(4.60)$ \\
International & $1.87(0.42)$ & $31.65(5.64)$ \\
Other & $1.77(0.31)$ & $30.42(4.41)$ \\
All funds & $1.58(0.37)$ & $27.43(5.11)$ \\
\hline
\end{tabular}

Assumed annual rate of return on assets 10 per cent and annual rate of growth of contribution 7 per cent. Source: I-NET Bridge in association with MoneyMate, and author's calculations.

between the cheapest and the most expensive might be regarded as unacceptably high, particularly as the impact of cost is unlikely to loom large in the mind of most prospective policyholders.

Analysis was carried out across charge types, commission, asset-based charges and administration charges. Patterns between providers were markedly different, suggesting a lack of competitiveness and transparency across the industry.

\section{Unit trust products}

South African unit trusts are likely to play a leading role in retirement funding, says Di Turpin, executive vice-chairman of the Association of Collective Investments. 'Because of their simplicity, transparency, flexibility and cost effectiveness, unit trusts are being used increasingly as a fundamental building block of virtually any investment and retirement vehicle today' (author's emphasis). ${ }^{29}$

\section{Methodology and data}

Data have been provided by I-NET Bridge in association with MoneyMate covering the period 2002-2003. Of the 457 funds on the MoneyMate database,
369 are included in the charges database. Thirty-four of these have been discarded from the analysis for reasons including charges expressed as a range or as a weighted average of domestic and international holdings; performance-based charges; initial charges that depend on the size of the investment; and a few cases of zero charges throughout. This leaves 335 funds with complete and reliable initial and annual charges.

The data cover the whole of the unit trust industry, not just the portion with tax benefits. This brings into question the relevance of the data set to retirement saving. The mix of asset classes suggests a savings pattern consistent with long-term retirement saving and fairly close to the corresponding mix in occupational funds and have elected to use it in total.

The methodology is as described in the section 'Methodology and parameters'. Charge ratios and reduction in yield have been calculated for every fund for 10-, 20-, 30- and 40-year saving terms.

\section{Results}

Table 6 provides the reduction in yield and charge ratio for each category over a 40 -year investment period. ${ }^{30}$ The average reduction in yield without weighting for assets under management is 1.58 per cent 
Table 7: Summary comparison of South African savings channels

\begin{tabular}{lllll}
\hline & Charge ratio (\%) & High & \multicolumn{2}{c}{ Reduction in yield (\%) } \\
Channel & Low & High & 1.65 \\
\hline Retirement funds (narrow range) & 17.0 & 27.1 & 1.04 & 2.36 \\
Retirement funds (wide range) & 13.4 & 38.4 & 0.81 & 2.80 \\
Individual policies & 26.7 & 43.2 & 1.50 & 1.95 \\
Unit trust products & 22.3 & 32.5 & 1.20 & \\
\hline
\end{tabular}

Note: These figures are not designed to be directly comparable. Definitions of ranges, in particular, have been determined in different ways and are intended to give a reasonable impression of the spread of results. Source: Various sources as disclosed in the main text.

per annum, equivalent to a charge ratio of just under 27.5 per cent. Standard deviations across all unit trusts are 0.37 per cent and 5.1 per cent for the reduction in yield and charge ratios respectively.

The analysis shows an intuitive relationship between the charges for each class of assets. Cash funds are cheapest, followed by bond funds and those that describe themselves as 'income funds'. Balanced, equity, international and all other funds are fairly closely bunched, with the exception of funds that could be identified as passively managed, which have overall charge levels closer to the cash and bond funds. ${ }^{31}$

The analysis suggests that the unit trust industry offers fair value for money to retirement savers. A reduction in yield range of 1.20-1.95 per cent captures a substantial proportion of South African unit trust funds and there is little reason to suggest that funds earmarked for retirement are significantly cheaper or more expensive. These figures are equivalent to charge ratios of 22.3-32.5 per cent.

\section{Summary}

Table 7 summarises the analysis of South African costs. Comparison across channels is difficult. There are differences in calculation methodology, data sources, employer sponsorship and the flexibility available to savers. The comparison of unit trust products to individual policies has been criticised as meaningless because it ignores the fact that tax-deductible unit trust products are not actively marketed while the life offices have a considerable network of advisers to support.

It is nevertheless clear that individual policies are generally more expensive than unit trust products, in turn more expensive than occupational funds.

\section{International comparison}

What is more concerning is that all of these vehicles appear expensive against international benchmarks. Again, comparison is difficult: very few national pension systems are directly comparable with South Africa's and the international research focus has been on these systems rather than on the unit trust or insurance alternatives. ${ }^{32}$

Overall, however, South Africa's occupational system does not compare well with international counterparts, despite its relative maturity and significance in the national economy. Nearly all countries studied experienced lower average costs than South Africa, the exception being Croatia, with a young and inefficient system, and parts of the Australian system where choice and flexibility is high.

The unit trust industry appears to compare well with the alternatives considered, notably the US mutual funds 
industry. Life insurance products, on the other hand, compare poorly with international alternatives. Commentators in South Africa have suggested that this is in part due to low average contributions and short average policy terms.

\section{Policy implications and further research}

'Financial regulators and supervisors are confronted with an increasingly complex global environment in which the traditional distinctions between financial institutions and between banking and other types of financial activity are blurred. The complexity of the financial environment is increased by the speed with which portfolios can change, and by the globalisation of the operations of major financial institutions and markets outpacing the national accounting, legal and supervisory systems on which safety and soundness of individual institutions and financial systems rely. ${ }^{33}$

A number of policy alternatives suggest themselves.

\section{Closure of channels}

This paper does not recommend the closure of any of the channels based on cost alone, or the removal of the tax concessions currently offered to individuals saving in any of these channels. Each vehicle offers a particular type of saving and they vary in their flexibility with respect to savings level and investment choice.

\section{Consistent disclosure of costs}

Costs are not transparent. This is particularly so in the life insurance and retirement funds environments. Difficulties as a researcher gathering data suggest that industry consumers would find it very challenging to compare providers on the basis of cost.

Life insurance products require policy value projections but these are not sufficient to claim transparency of costs to the consumer. The unit trust industry is better, helped by having a less complicated range of charges, but here again, information would be improved by providing consistently calculated summary ratios, with clear definition of terminology.

The issue is more complex in the retirement funds environment, but trustees retain fiduciary responsibility to ensure that funds are well managed and this includes control over costs. They should gather all the information required to ensure that costs incurred by the fund are reasonable. Initiatives that would accelerate this process include:

- clear reporting requirements from the regulator, the Financial Services Board;

- industry analysis to enable trustees to measure fund expenses against appropriate benchmarks;

- a requirement that asset management charges be disclosed separately from gross investment performance;

- industry initiatives increasing the awareness of the impact of costs and recommending minimum disclosure to members, including discussion of the impact of costs on member benefits.

The reporting requirements of the Canadian Joint Forum of Capital Market Regulators $^{34}$ for defined contribution arrangements might serve as a useful starting point. In the longer term, consistent measurement and publication of charges across all parts of the industry is surely attainable and should be pursued by the regulatory authorities.

\section{Cost limitations}

There are a number of cases in which regulatory authorities have imposed cost ceilings on providers, with mixed success. 
In the complex South African environment, cost ceilings would be difficult to apply. A consistent measure of pricing would need to be developed and careful analysis undertaken regarding the level of any proposed ceiling. The consequences of the ceiling would need to be considered as carefully as possible before implementation, and measured as well as possible thereafter. Regular review of the system would be required.

Cost ceilings may be more appropriate in the case of a newly created class of products, such as Stakeholder in the UK.

\section{New class of products}

The high-profile launch of the Stakeholder range of pensions saving products in the UK makes an equivalent in South Africa an attractive option. But Stakeholder is just one option: a privately managed, funded, voluntary system.

Another option might be a national provident fund, in line with many of the defined contribution arrangements in South Africa, but centrally managed to ensure economies of scale. If a new class of products were to be set up, whatever form it took, it should at least be straightforward to understand and implement, inexpensive to run, and designed for the benefit of the savers. It should also dovetail with existing arrangements, reducing the potential for unintended consequences like lower saving in other areas.

\section{Lessons from overseas}

Many of the benefits to be gained from observation of experience outside of South Africa can only be applied to a mandatory system, or at least a voluntary system with considerable national reach. For completeness, however, these lessons are listed as a reminder of the policy steps that might bring benefit to the South African environment:
- centralise elements of retirement savings administration;

- look for ways to develop economies of scale;

- restrict the set of allowable charges;

- find ways to impose limits on marketing costs;

- establish limitations on portfolio freedom that reduce costs without unduly restricting investment choice;

- shift costs to other areas, by postponing them to later generations or by moving them to other parts of the economy;

- find ways to cross-subsidise the low-income earners.

\section{Further research}

This analysis represents the first attempt in South Africa to measure administration costs in a consistent manner across channels. The publicity that it has generated, both in the personal finance press and in policymaking circles surely demonstrates this. Consideration should be given to further research in a number of areas:

- Obtain and analyse deeper, more wide-ranging data, particularly in the occupational funds industry.

- Consider the impact of violations of the assumption of lifetime contributions and seek to understand actual South African saving patterns.

- Investigate the return-reducing impacts of implicit costs in investment products.

- Conduct a deeper comparison of the channels, taking into account differences in the design and objectives of the alternatives.

- Consider in more detail the links between charges and policy: how to spread total costs across a system is complex, economically and philosophically.

'Some analysts treat lowering administrative charges as the only goal of 
designing a pension system. I have tried to spell out the important trade-offs involved. Lower administrative charges can involve substantial constraints on individual choice of pension provider and of pension-fund portfolio and limits on competition. This conflicts with other goals of pension reforms and might adversely affect pension funds' net rate of return. ${ }^{35}$

This report sheds some light on the costs of saving for retirement, but these costs are only one piece in a complex puzzle affecting the prosperity of South Africa's citizens in their golden years.

\section{Acknowledgments}

This research has received financial assistance from the Actuarial Society of South Africa, gratefully acknowledged, but it has been carried out independently of the Actuarial Society and the author's employer, SEI Investments. The author could not have completed this research without a great deal of assistance, received with gratitude. The responsibility for any errors in analysis and interpretation is entirely the author's.

\section{References}

1 South African Government (2002) 'Transforming the Present - Protecting the Future', Report of the Committee of Inquiry into a Comprehensive System of Social Security for South Africa (Taylor), Consolidated Report.

2 HelpAge International (2003) 'Non-contributory Pensions and Poverty Prevention: A Comparative Study of Brazil and South Africa', supported by the United Kingdom Department for International Development.

3 Ferreira, M. (1999) 'The generosity and universality of South Africa's social pension system', The ACP-EU Courier, No 176, July-August, pp. 55-56.

4 HelpAge International (2003) op. cit.

5 Ferreira (1999) op. cit, p. 55.

6 South African Government (2002) op. cit.

7 This study was first presented, in a significantly longer format, to the 2004 Convention of the Actuarial Society of South Africa. The publicity that it generated, from extensive coverage by the personal finance press, to an appearance by the author to the Finance Committee of Parliament, suggests that the objectives of the analysis are being met and that policymakers are paying attention.

8 A 1 per cent of assets annual management fee is equivalent to 14.13 per cent of every premium over a 30 -year policy and a 2 per cent fee equivalent to 25.90 per cent, assuming contribution growth of 7 per cent pa and investment return 10 per cent pa. The corresponding figures over a 40-year policy are respectively 18.94 per cent and 33.70 per cent.

9 Whitehouse, E. (2000) 'Administrative charges for funded pensions: An international comparison and assessment', World Bank Social Protection Discussion Paper Series.

10 Murthi, M., Orszag, J. M. and Orszag, P. (1999) 'Administration costs under a decentralised approach to individual accounts: Lessons from the UK', World Bank, presented at New Ideas About Old Age Security World Bank conference, Washington DC, 14th-15th September.

11 James, E., Smalhout, J. and Vittas, D. (2001) 'Administrative costs and the organization of individual account systems: A comparative perspective', in 'New Ideas about Old Age Security', Holtzmann, R. and Stiglitz, J. (eds), World Bank, Washington DC.

12 Devesa-Carpio, J., Rodriguez-Barrera, R. and Vidal-Meliß, C. (2003) 'Administration costs for the affiliate in individual account systems: Assessment and international comparison', University of Valencia, Spain, Mimeo.

13 Diamond, P. (1999) 'Administrative costs and equilibrium charges with individual accounts', National Bureau of Economic Research, Working Paper 7050.

14 Whitehouse (2000) op. cit.

15 Ibid.

16 Devesa-Carpio et al. (2003) op. cit.

17 For example, most policies impose a monthly rand deduction called a policy fee. This is a relatively small amount, but is rarely fixed for the duration of the policy. Inflationary increases to the policy fee are more easily modelled through the model than through a formula.

18 This was tested when setting up the model and separately when analysing each of the product types described in the analysis of costs section.

19 Murthi et al. (1999) op. cit.

20 James et al. (2001) op. cit.

21 Trustees of occupational retirement funds are limited to investing 75 per cent of the assets of the fund in equities, for example.

22 Readers are referred to the annual reports of the Registrar of Pension Funds, available at the website of the Financial Services Board, for more information on the South African retirement fund environment (www.fsb.co.za).

23 Registrar of Pension Funds (2002) 'Forty-third Annual Report 2002', Financial Services Board, South Africa.

24 Registrar of Pension Funds (2003) 'Forty-fourth Annual Report 2002', Financial Services Board, South Africa.

25 The effective date of the Alexander Forbes survey is 31st December, 2001.

26 The sample has smaller funds than the set of self-administered funds as a whole, which may help to explain the difference.

27 Occupational retirement funds are subject to a 
bewildering array of costs as listed in the Registrar's report. Examples of these costs include salaries, rent and office expenses, auditors' fees, secretarial fees and an item referred to by the Registrar as 'all other fees' include items from Financial Service Board levies to trustee training costs.

28 The average contributions to policies lie comfortably within the range of R200 to R1,000 suggested by these model points.

29 Turpin, D. (2003) 'Likely leading role in retirement funding', Business Day, 26th November, p. 20 (http://www.businessday.co.za/articles/TarkArticle. aspx?ID $=908742$ ).

30 This period is surely unrealistically long for a savings vehicle as flexible as the unit trust, but it provides the basis for comparison with other products and with the results of international studies. Corresponding figures for other investment periods are in the appendix.

31 Closer analysis of the passively managed funds shows that they are more expensive than bond funds at short terms and cheaper at long terms. This reflects their higher average initial charge than the bond funds and lower average annual charge.

32 A number of authors need to be acknowledged for the cost analysis of various international systems: Anusic, Z., O'Keefe, P. and Madzarevoc-Sujster, S. (2003) 'Pension reform in Croatia', World Bank Social Protection Discussion Paper Series 0304; Andrews, E. (2001) 'Kazakhstan: An ambitious pension reform', World Bank Financial Sector Development Department; Chlon, A., Gra, M. and Rutkowski, M. (1999) 'Shaping pension reform in Poland: Security through diversity', World Bank Social Protection Discussion Paper Series 9923; Devesa-Carpio et al. (2003) op. cit; Diamond (1999) op. cit; Fornero, E., Fugazza, C. and Ponzetto, G. (2004) 'A comparative analysis of the cost of Italian individual pension plans', Center for Research on Pensions and Welfare Policies, Working Paper 33/04; James et al. (2001) op. cit; Lasagabaster, E., Rocha, R. and Wiese, P. (2002) 'Czech pension system: Challenges and reform options', World Bank Social Protection Discussion Paper Series 0217; Mitchell, O. and Bateman, H. (2003) 'New evidence on pension plan design and administration expenses: The Australian Experience', University of New South Wales; Murthi et al. (1999) op. cit; Rocha, R. and Vittas, D. (2001) 'The Hungarian Pension reform: A preliminary assessment of the first years of implementation', World Bank Policy Research Working Paper 2631; and Whitehouse (2000) op. cit 33 Marcus, G. (2002) 'Financial Services Board Annual Report 2002', Financial Services Board of South Africa.

34 Canadian Joint Forum of Financial Market Regulators (2004) 'Guidelines for Capital Accumulation Plans', 28th May, Joint Forum of Financial Market Regulators, Canada.

35 Whitehouse (2000) op. cit. 